dying. These themes could be readily addressed through a variety of teaching styles and will influence the Buckingham Medical School palliative care curriculum.

\section{IS THE EELCA PROGRAM A GOOD LEARNING SUPPORT FOR SPANISH PROFESSIONALS?}

Maria Teresa Garcia-Baquero Merino, C. Perez de Oteyza, Alfredo Dominguez Cruz, Javier Fiz Galende, Alberto Tarrãno, Antonio Ciardo. Universidad Catolica San Antonio de Murcia and Greenwich and Bexley Community Hospice, Hospital General Universitario Gregorio Marañon, Hospital Universitario Getafe, Hospital Fundación Jiménez Díaz, AECC, AC Osteopatia

\subsection{6/bmjspcare-2018-ASPabstracts.52}

B. The eELCA program has been well used to support and further learning in End of Life in the UK in a range of Health and Social care facilities

A. To determine whether the contents and model of eELCA are transferable to suitable group of Spanish professionals

M. We analise a 40 strong cohort of multidisciplinary, multi-level learners looking at data regarding accessibility frequency, hours of module study, end of course survey results, ad hoc comments and requests over the 12 months, recommended reading list use, and the personal individual learning commentaries and reflective practice incorporation. These data were the basis of multivariable knowledge and conceptual algorithms used to compare with those obtained from Spanish Master degrees

C. Those professionals who had access to eELCA had a significantly superior learning curve in 12 months to other courses. e ELCA seems to be an extremely useful program for Spanish learners, although they would like some modules to incorporate Spanish regional and local information.

\section{GABAPENTIN AND PREGABALIN USE, MISUSE AND ASSOCIATED RISKS IN THE PALLIATIVE CARE SETTING}

M Doherty, R McQuillan. Department of Palliative Care, Beaumont Hospital, Dublin

\subsection{6/bmjspcare-2018-ASPabstracts.53}

Background Gabapentin and pregabalin are antiepileptic medications licensed for the treatment of neuropathic pain. The Department of Health has highlighted the need for vigilance when prescribing these medications due to their misuse and associated risks: dependency, CNS depression, seizure activity and mortality. Furthermore, due to the frequency of withdrawal symptoms, the manufacturers have recommended that pregabalin should be weaned gradually over a minimum of one week.

Objectives To;

- Assess prescribing practices, frequency of misuse and frequency of serious adverse events in relation to gabapentin/ pregabalin in the palliative care setting

- Methods

- An anonymous survey was designed and administered using SurveyMonkey. It was distributed via email link to palliative medicine physicians (PMPs) and palliative care nurse specialists (PCNSs)
Results 49 responses were received- 36 from PMPs, 13 from PCNSs. 48/49 respondents prescribe or advise gabapentin/pregabalin. $94 \%$ of respondents prescribe pregabalin more frequently than gabapentin. When discontinuing gabapentin/ pregabalin, $16 \%$ stop without weaning, $6 \%$ wean over three days, 20\% wean over one week, 56\% wean over one week or more. Seizure activity and respiratory depression secondary to gabapentin/pregabalin was reported by $6 \%(3 / 49)$ of respondents. $8 \%(4 / 49)$ of respondents reported that they suspected or believed some of their patients to have misused gabapentin/pregabalin- none reported their concerns to the UK Committee on the Safety of Medicines or the Health Products Regulatory Authority.

Conclusions Gabapentin and pregabalin are commonly prescribed in palliative care, practices vary with regard to weaning the medications, and serious adverse events and misuse of these medications are occurring but are not being reported. Respondents displayed a growing awareness of the abuse potential of these medications in the comments section of the survey and report having modified their prescribing practices on account of this.

\section{I DON'T KNOW WHAT TO SAY': COMMUNICATION AT THE END OF LIFE - WORKSHOPS FOR FOUNDATION DOCTORS}

Beverley Lee, Amy Pharaoh, Andi Stone, Claire MacLachlan. Forest Holme Hospice, Poole Hospital NHS Foundation Trust

\subsection{6/bmjspcare-2018-ASPabstracts.54}

Background Effective Communication skills are imperative for good patient care. Communication with patients and relatives can be challenging in a busy hospital environment. Juniors have extensive training throughout medical school, but little after qualifying. however, they are often involved in these end of life discussions.

Methods As part of their education programme,all Foundation Year 1 Doctors at Poole Hospital NHS Foundation Trust attend a small group workshop (4-6 participants) facilitated by a Palliative Medicine Consultant and Specialist Nurses in Palliative and End of Life Care. Workshops run every month to allow all 28 FY1 Doctors to attend.

each 3 hour session comprises:

- Principles of good communication, challenges andindividual experience.

- Observation of facilitator acted role play

- individual role play with a nurse actor. peer and facilitator feedback.

Communication scenarios include breaking bad news, DNACPR, ACP and discussing dying.

Evaluation includes questionnaire on completion of the workshop and a follow up 3 months later.

Results in 2016 all 28 (100\%) FY1 Doctors attended a workshop. $100 \%$ completed a survey on completion of the workshop and 54\% completed a follow-up survey at 3 months. Feedback was very positive with 93\% rating facilitation as excellent and 7\% as very good.

Supportive, constructive, real-time feedback given by approachable, knowledgeable staff was appreciated. FY1 Doctors reported training was not too early after qualifying, giving them opportunity to practice conversations in a relaxed 